\title{
DESIGN, DEVELOPMENT AND PERFORMANCE OF OPTIMUM WATER SOFTENER
}

\author{
Ahmed Sharjeel*, Shafiq Anwar, Abdul Nasir, Haroon Rashid \\ Department of Structures and Environmental Engineering, University of Agriculture Faisalabad, Pakistan \\ *Corresponding Author Email: ahmed.sharjeel@hotmail.com
}

This is an open access article distributed under the Creative Commons Attribution License, which permits unrestricted use, distribution, and reproduction in any medium, provided the original work is properly cited.

\section{ARTICLE DETAILS}

\section{Article History:}

Received 24 November 2018 Accepted 25 December 2018 Available online 7 February 2019

\section{ABSTRACT}

\begin{abstract}
Water is an important factor of life for all living organisms and it is now deteriorated very rapidly due to industrial effluents, municipal and agriculture waste leaching down the groundwater. The percolation of water through the deposits of limestone and chalk which are largely made up of calcium and magnesium carbonates increases the mineral contents. So, the presence of high mineral contents creates water hardness. Water hardness is mainly occurring by the existence of calcium and magnesium, their high concentration in water makes water hard which cause several hazardous impacts on human life. Therefore, certain concentration standard limits have been fixed by different organizations. According to WHO $500 \mathrm{mg} / \mathrm{l}$ is allowable limit for water hardness. So regular use of high concentration of Calcium and magnesium ions above standard limits is causing real problems for human beings and environment. In daily routine life different harmful incidence occurs due to hard water. To overcome this problem water softening is a technique that serves the removal of cations which are most likely the hardness factors are calcium and magnesium. Water softening is the most useful technique to remove hardness. Therefore, a water softener is developed for domestic purpose. As the development of an optimum water softener was very essential for domestic use. The water softener can have performed efficiently with a hardness range of $1000-1200 \mathrm{mg} / \mathrm{l}$ and TDS may be up to $1500 \mathrm{mg} / \mathrm{l}$. The water softener plant is also cost efficient that have almost one-time production cost and very low maintenance and running cost. After the manufacturing of water softening plant hardness, $\mathrm{pH}$, DO, TDS and EC is calculated to check its efficiency. The hardness, TDS and conductivity reduces after passing the sample water through the sample, DO was increased to little extent and $\mathrm{pH}$ was remained in a specific range.
\end{abstract}

\section{KEYWORDS}

Water Softening, Total hardness, Calcium and magnesium, Carbonates and bicarbonates, Ion exchange resin and Regeneration

\section{INTRODUCTION}

Water is an extremely important element of our environment. It is mainly considered as the main source that keeps creatures alive in the earth. It is very essential for living things [1]. If we define it generally; water is a transparent fluid which makes the world's streams, lakes, oceans and rain and is the major constituent of the fluids of living things. Water is also widely used as major resource in manufacturing plants and different industries. This water contains many undesirable things which is termed as impurities. As water contains many impurities amongst them most attentive are hardness, bacteria, microorganisms, virus, sediments, dissolved salts, dissolved gases, suspended solids, odor, arsenic, iron, copper, turbidity etc. Among this hardness is our main concern as it effects in many ways in our life. The metal ions present in water causes water hardness. High mineral contents in water can create lots of health issues to humans [2]. Calcium and magnesium are considered as two main components of hard water which cause the hardness in water. Water can be considered hard when the concentration of calcium and magnesium is found to be above a permissible limit (120 mg/l) [3].

According to Pakistan Standards Quality and Control Authority; Water Quality Standards, the maximum acceptable value for hard water is 500 $\mathrm{mg} / \mathrm{l}$ [4]. It contains minerals $\mathrm{Ca} 2+$ and $\mathrm{Mg} 2+$ which can be easily deposited on the surfaces of equipment such as kettles, coffee makers, and heaters in the form of scale. The formation of scale causes clogging of a piping system thus lowering the water flow [5]. While causing pipe clogging, however, it tends to protect their surfaces by coating to prevent corrosion [6]. Besides this, it also decreases the foamy nature of soap and detergent soapy, leading to the use of additional soap to wash utensils and clothes, as well as in bathing $[7,8]$.

Calcium occurrence in water is due to its passage over limestone, dolomite, gypsum and gypsiferous shale. The range of calcium content is from zero to hundreds of milligrams per litre. The concentration is depending upon the source and treatment of water. The presence of calcium in water results the corrosion of metal pipes. On other hand, considerable calcium salts, precipitate on heating to form a harmful scale in boilers, pipes and cooking utensils.

Magnesium is the common constituent of natural water and it ranks eighth most abundant among the elements. The association of water with granite or siliceous sand may contain less than $5 \mathrm{mg}$ of magnesium per liter. Water having dolomite or magnesium-rich limestone may contain $10-50 \mathrm{mg} / \mathrm{l}$, and concentration in hundreds of $\mathrm{mg} / \mathrm{l}$ of magnesium may be present in water that has been in contact with deposits containing sulfates and chlorides of magnesium. 
Magnesium with similar action of calcium creates the property of hardness to water. Basically, the water hardness was considered as the measure of capacity of water to precipitate soap. But after recent practices the sum of calcium and magnesium concentration is now considered as the total hardness.

Water is considered as hard when the presence of calcium and magnesium concentration is above permissible limit. According to the United States Geological Survey the classification of hard water is given as the concentration between $0-60 \mathrm{mg} / \mathrm{l}$ is considered as soft water, moderately hard range is $61-120 \mathrm{mg} / \mathrm{l}$, hard water range is $121-180 \mathrm{mg} / \mathrm{l}$ and concentration above $180 \mathrm{mg} / \mathrm{l}$ is considered as very hard water. The hardest water which occurs naturally is considered as seawater because it contains different salts. The seawater hardness concentration is considered as $6630 \mathrm{mg} / \mathrm{l}$ while of fresh water is ranging from $15-375 \mathrm{mg} / \mathrm{l}$ [9].

Variety of problems caused by the presence of certain metal ions like calcium and magnesium primarily as bicarbonates, chlorides, and sulfates in water [10]. Promotion of galvanic corrosion and foul of plumbing is occur due to buildup of lime scale which is due to hard water. From regeneration process in industrial scale water softening plants, the discharge flow can precipitate scale that can interfere with sewage systems [11]. While using soap a slippery feeling is experienced with soft water that happens because soaps incline to bind to fats in the surface layers of skin, creating soap molecules difficult to remove by simple dilution. On the other hand, in hard-water areas insoluble salts formed due to presence of calcium or magnesium ions, which commendably removing the residual soap from the skin but possibly leaving a coating of insoluble stearates on tub and shower surfaces, which is called soap scum [12]. From person to person these effects is identified more or less necessary, addition of chemicals like baking soda, calcium chloride or magnesium sulphate taken place for those who dislike the sliminess and difficulty of washing off soap caused by soft water may harden the water [13].

Hard water also causes formation of scale inside boiler and its pipeline. Boilers generate steam in industries which tend to be very expensive. Hard water reduces heat efficiency and lifetime if used in boilers. Sometimes it causes serious accident like explosion of boilers. It changes the shade of fabrics in dyeing. Hard water make soap insoluble and re decompose dust of clothes during washing and make them yellowish. Hard water found sometime incompatible with finishing chemicals. Hard water also decomposes bleaching agents.

Therefore, water treatment plant is very necessary to soft hard water, to make water suitable for different necessities. The treatment of water to make it soft is known as water softening. Water softening also improves the quality of water to use it for different specific purposes. There are many processes to make water soft, such as ion-exchange method, soda lime process, demineralization but ion-exchange method is most widely used process for water softening. Water softening method is based on the removal of metal ions present in water. Therefore, we have to make best treatment plant depending on cost, duration of operation, durability, capacity and overall efficiency.

The basic procedure for the ion exchange method is the use of resin in which the hardness ions most probably $\mathrm{Ca} 2+$ and $\mathrm{Mg} 2+$ are exchanged with sodium ions [14]. The hardness is reduced by ion exchange devices by replacing calcium and magnesium with sodium and potassium ions [15]. The divalent cation $(\mathrm{Ca}++)$ bind more intensely than monovalent cation $(\mathrm{Na}+)$ with ion exchange resin which are organic polymer containing anionic functional group. Zeolites are inorganic materials which can be used to exhibit ion exchange properties. In laundry detergents these minerals are used widely. Resins are also used to remove carbonate, bicarbonate, sulphate ions which are captivated, and hydroxide ion released from the resin.

A solution of sodium chloride or sodium hydroxide depending upon the type of resin is used to recharge by eluting the calcium $\mathrm{Ca} 2+$ and magnesium $\mathrm{Mg} 2+$ ion when all the available $\mathrm{Na}+$ ion have been replaced by calcium and magnesium ions [16]

\section{MATERIAL AND METHOD}

This study was conducted to develop and fabricate an optimum water softener plant. It was an effort to manufacture an appropriate water softener which can be used easily, effectively and properly to eradicate the hard water impacts on human health and environment at domestic and other relevant places. Hard water has become a critical issue in our daily water use. As we discussed hard water causing lot of problems at home with our utensils, cloths, plumbing with our skin, hairs and effects our body internally as well. Hard water also has various hazardous impacts on industry as well.

\subsection{Design and development of water softener}

For the development of water softener, it was firstly designed on AutoCAD with consideration of all-important designing factors. It was considered to make such a design which is compatible and occupy less space in domestic use and utilize already exist important components at home. A brief description of the major parts comprising the softener is given below:

The main component of the softener is a skid which is made up of mild steel square pipe of $1.905 \mathrm{~cm}(0.75 \mathrm{inch})$ size. The length of skid is $135 \mathrm{~cm}$ and its height are $112 \mathrm{~cm}$. The skid is used for the occupation of all main components of the softener. A media vessel of $10 " \times 54$ " size which is a poly glass vessel, inner shell is made up of polyethylene with threaded inlet the height of vessel is $139.2 \mathrm{~cm}$ and its capacity is 62 liters. Two polypropylene filters of 5 microns are used with housings which are installed before and after the ion exchange process. A tank of 500 liters capacity is placed before the plant to feed raw water to the softener. A feed pump of $0.5 \mathrm{HP}$ is installed to pump the raw water from 500 liters tank. There is also a recharge tank of 80 liters capacity which is used for the solution of regeneration of ion exchange resins.

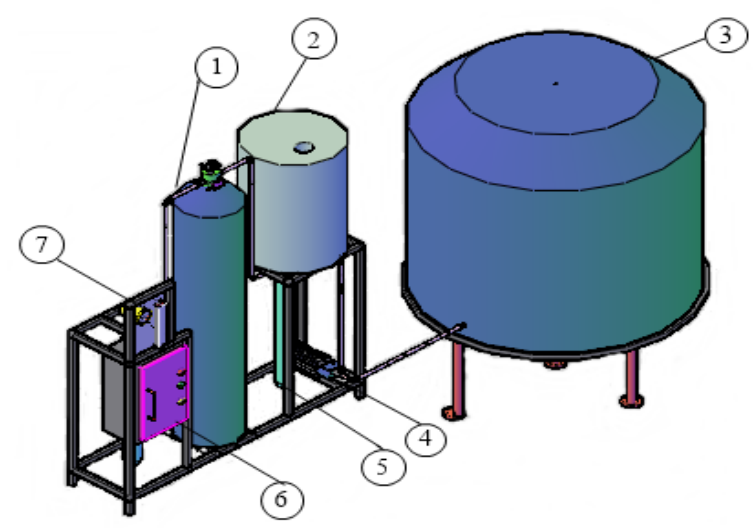

Figure 1: An isometric view of water softener

1. Media vessel with multiport valve

2. Recharge tank

3. Raw water tank

4. Pump

5. PPF filter

6. $\quad$ Electric panel

7. Flow meter \& pressure gauge

\subsection{Determination of Physio-chemical parameters}

Water samples were analyzed for various physio-chemical parameters. $\mathrm{pH}$ was determined by using pH meter while EC and TDS by HANNA HI 99300 meter directly [17]. Hardness was determined by titration method while DO was determined by using OHAUS starter 300d DO meter. 
In a $50 \mathrm{ml}$ water sample added $1 \mathrm{ml}$ ammonia buffer solution then added 5 drops of Erichrome Black $\mathrm{T}$ as an indicator, wine red color appeared by adding indicator. Then titrated it against 0.01M EDTA solution until the color changed into purple. The used volume of EDTA from the burette was multiplied by 20 which gave the amount of total hardness in milligram per liter.

\subsection{Water Softening}

Water softening is done by the process of ion exchange method; in which ion exchange resins are used. These resins are small plastic beads which are composed of organic polymer chains that have positive or negative charged functional group. Cation exchange and anion exchange are two types of resin beads which have negative and positive functional group respectively. We have used cation exchange resins for water softening. During this operation the raw water is passed through the resin media in the vessel. The calcium $(\mathrm{Ca}++)$ and magnesium $(\mathrm{Mg++})$ ions in water exchanged with sodium $(\mathrm{Na}+)$ ions which are provisionally stored in resin beads.

\subsection{Regenerating ion exchange resin beads}

Ultimately the removal capacity of ion exchange resin becomes exhausted therefore resins need to be regenerated. This all operation of regeneration and softening is controlled by multi-functional flow control valve. The process of regeneration has several steps and it is beginning with backwashing of the resins. This rapid backwash does not regenerate ion exchange resins and it only gives a physical cleaning of the outside of the media, this can be done in 5-10 minutes. The next step is called regeneration in which a brine solution of sodium chloride is formed in 80liter recharge tank and then it is passed through the vessel of resin beads. The sodium from the brine solution invades the resin pores and displaces with Calcium and magnesium ion contaminants and recharge the resin beads after 30 minutes. In the next 5-10 minutes the brine solution refills the recharge tank from the vessel. In next step the influent water is allowed rinse fast through the vessel that settles the medium and refresh the ion exchange resin beads. After that the filtration starts normally and hard water passed through the media vessel and filtered out as soft water.

\section{RESULTS AND DISCUSSION}

An optimum water softening plant is developed for domestic purpose to overcome the different effect of hard water on human being and environment. The performance of water softener is tested by considering different water quality parameters, such as hardness, total dissolved solids, $\mathrm{pH}$, electric conductivity and dissolved oxygen. According to our research study the main parameter of the research is water hardness. Therefore, the plant is developed on considering mainly the factor of hardness. The parameters were tested by different giving conditions first of all the efficiency of the system were tested using 15 liter resins then it was recharged for two times and then resins were replaced and used 25 liters, the analysis of each parameter has been discussed below:

\subsection{Total Hardness}

The hardness of feed water sample was $422 \mathrm{mg} / \mathrm{l}$; in first situation the feed water was passed through 15 liters of ion exchange resin. It shows that 10000 liters of water passed through that resin media to reach its highest value of hardness i.e. $422 \mathrm{mg} / \mathrm{l}$. In start the result shown that the hardness was reduced to $0 \mathrm{mg} / \mathrm{l}$ (Fig. 2). Then it was recharged for the first time and 8500 liters of water passed through the media to reach its highest value of hardness. The second recharging of resin was taking place after that it also passed 8500 liters of water to get to its highest value. After two recharging's the resin was changed and its quantity also increased to 25 liters, then hardness gets to its highest value of $422 \mathrm{mg} / \mathrm{l}$ after passing 19500 liters of water as shown in following figure.

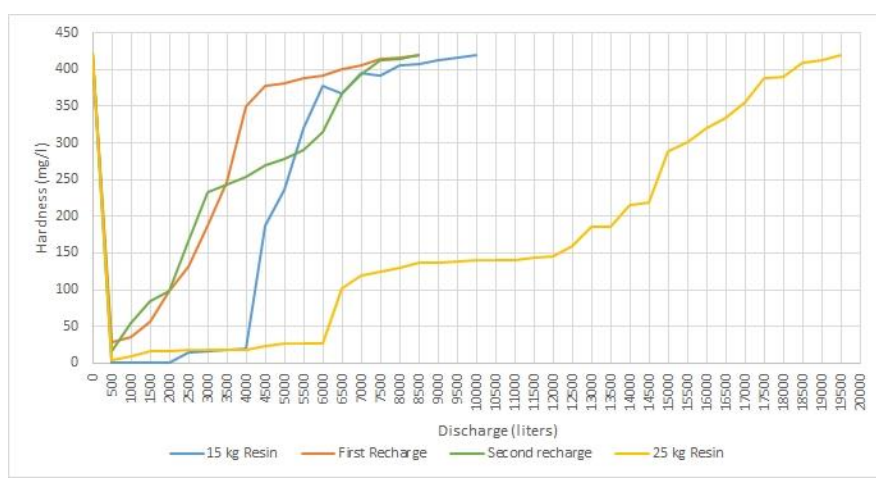

Figure 2: Results of Total Hardness

\subsection{Total Dissolved Solids}

In water softening plants TDS of feed water was $870 \mathrm{mg} / \mathrm{l}$ after passing through the system it was increased firstly due to backwash and gravels bed because it could have some contaminations. After passing sample water regularly, the TDS was decreased gradually.
In first trial the TDS was increased up to $1010 \mathrm{mg} / \mathrm{l}$ then it decreases to $885 \mathrm{mg} / \mathrm{l}$ with passage of sample water gradually. In second trial TDS was increased up to $1260 \mathrm{mg} / \mathrm{l}$ then it decreases to $890 \mathrm{mg} / \mathrm{l}$ after passage of 8500 liters water. Then in third and fourth trial the trend was the same and it reaches to $1470 \mathrm{mg} / \mathrm{l}$ to $916 \mathrm{mg} / \mathrm{l}$ and $970 \mathrm{mg} / \mathrm{l}$ to $892 \mathrm{mg} / \mathrm{l}$ respectively. The pattern has been shown in Figure 3 as given below.

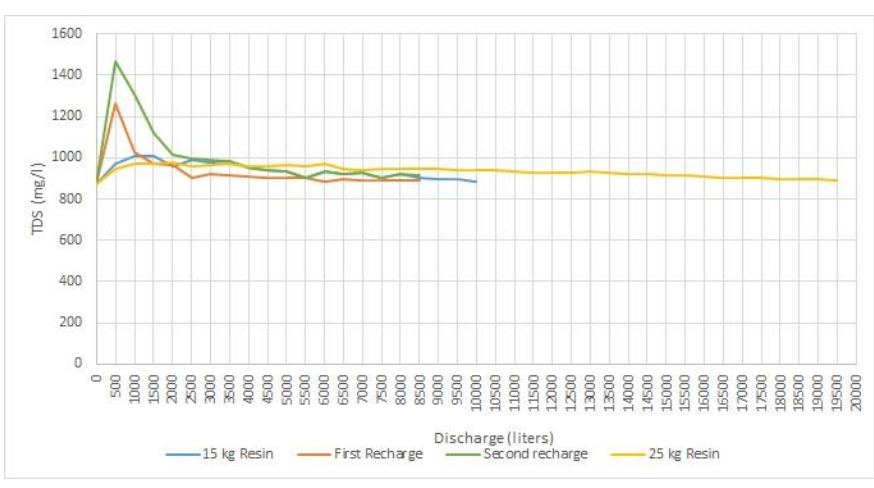

Figure 3: Results of Total Dissolved Solids 


\subsection{Electrical Conductivity}

EC of the water in first trial was ranging from 1830 to $1620 \mu \mathrm{s} / \mathrm{cm}$. While the feed water EC was $1645 \mu \mathrm{s} / \mathrm{cm}$. In the beginning the value of EC was increased up to $1830 \mu \mathrm{s} / \mathrm{cm}$ due to fresh gravels in the vessel which may have some mineral particles that can increase the conductivity. Then after passing more water and flushing off that minerals reduces the conductivity of water. In second trial the range of EC was 2301 to 1610 $\mu \mathrm{s} / \mathrm{cm}$. In this trial the value of EC increased even more as compared to first trial. This was happened due to solution of sodium chloride which was added during the process of regeneration. That increases the conductivity so much. Then after passing the water sample from poly propylene filters and ion exchange resin the value of electrical conductivity reduces to 1610 $\mu \mathrm{s} / \mathrm{cm}$.

In third trial EC of water was ranging from 2672 to $1578 \mu \mathrm{s} / \mathrm{cm}$. Similarly, the reason was same as the process of regeneration of media resins was done again in this test. When the value of hardness reached again to original value of sample water at $420 \mathrm{mg} / \mathrm{l}$ after passing 8500 liters of sample water and after two times regeneration of resin beads it was then decided to change resin and also increased the quantity upto 25 liters to test the efficiency of ion exchange resins. In this trial the tendency of the system increased, and 19500 liters sample water passes through to reach through the original value of hardness. Therefore, the conductivity of water in this trial ranges from 1746 to $1642 \mu \mathrm{s} / \mathrm{cm}$. As the new bed of resin was installed in this trial and no regeneration was took placed so conductivity was not increased as much relative to initial trials. So, the trend of electrical conductivity was decreasing in this water softener. Summary of electrical conductivity is shown in figure 4 .

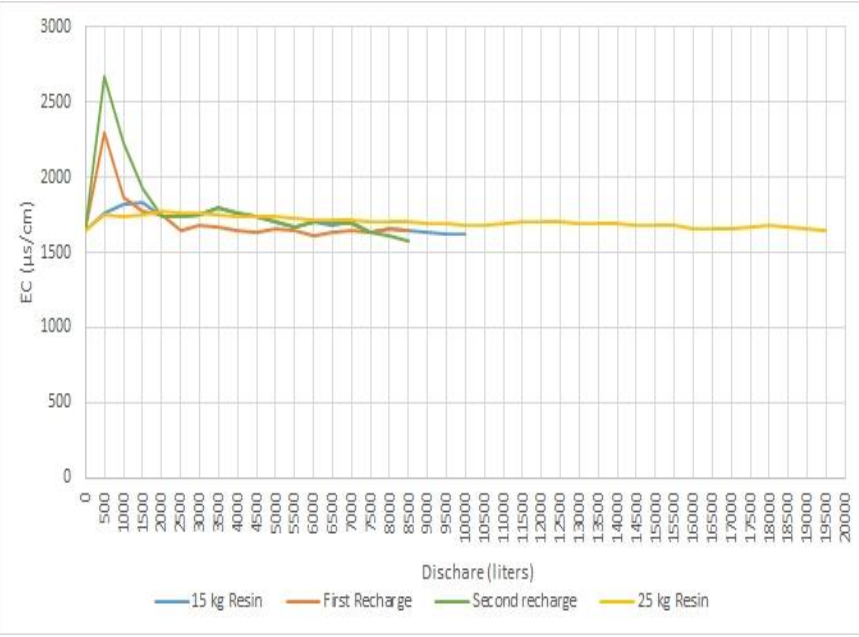

Figure 4: Results of Electrical Conductivity

\section{$3.4 \mathrm{pH}$}

In this study as we have four different trials in first trial when 15 liters resins were used the $\mathrm{pH}$ of the water was ranging from 6.6 to 6.9. The $\mathrm{pH}$ of sample water was 6.9. In second trial it was recharged for the first time and $\mathrm{pH}$ was increased up to 7.2 but the range was between 6.6 and 7.2. Then it was recharged again for the second time in third trial. The $\mathrm{pH}$ of the water was ranged from 6.6 to 6.9. In fourth trial it was decided to change and increase the quantity of resin up to 25 liters the value of $\mathrm{pH}$ from that test was ranging from 6.5 to 6.8 and by this test it was observed that more sample water was passed through the plant to reach through its original value of hardness. In this trial 19500 liters of water was passed to get to the value of $420 \mathrm{mg} / \mathrm{l}$ of hardness and $\mathrm{pH}$ was between 6.5 and 6.8 . The $\mathrm{pH}$ was in low range as the more quantity of resins were used in this test and they were also fresh. But in whole experiment it was observed that the $\mathrm{pH}$ of water sample through plant was fluctuating randomly but it was remaining in a specific range. The $\mathrm{pH}$ of feed water was 6.9 and by passing through plant it was observed between 6.6 and 7.2. Following graph shows the pattern of $\mathrm{pH}$ (Figure 5).

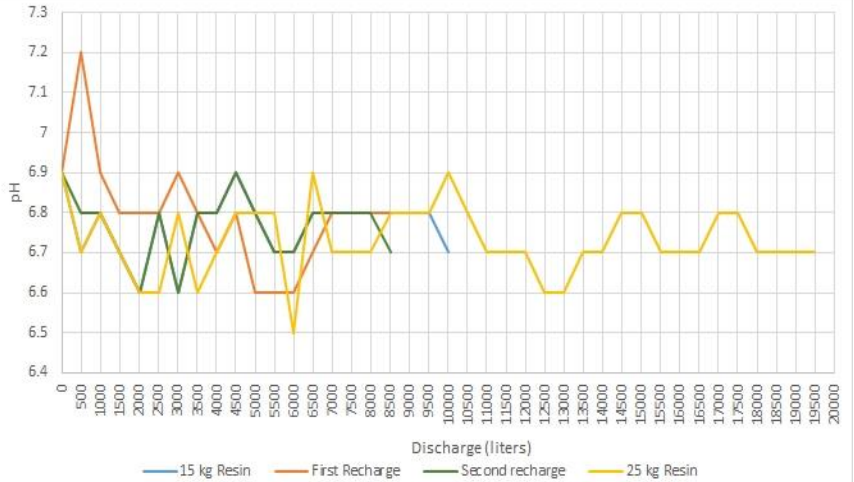

Figure 5: Results of $\mathrm{pH}$

\subsection{Dissolved Oxygen}

Dissolved Oxygen of feed water was 1.74 and in water softening plant it was increased gradually. In first trial 10000 liters of water passed through and DO was ranging from 1.62 to $2.05 \mathrm{mg} / \mathrm{l}$. In the beginning of the experiment DO was decreased but after passing more water it increased gradually. In second trial when first recharge of resins was taking place 8500 liters water was passed through it and DO observed was increased upto $1.92 \mathrm{mg} / \mathrm{l}$ but it was ranging from 0.81 to $1.92 \mathrm{mg} / \mathrm{l}$. After second recharge in third trial DO range were observed from 1.06 to $1.69 \mathrm{mg} / \mathrm{l}$. Then after that resins were changed and increased the quantity from 15 to 25 liters which gives the value of DO from 0.88 to $2.09 \mathrm{mg} / \mathrm{l}$. In this test it was observed that DO was increased bit more than initial trials as there were more quantity of water passed through due to increase in efficiency of the system. There were 19500 liters of water passed to reach the original value of hardness. So, the trend observed of DO in this experiment was increasing with increasing discharge of water sample from the water softener (Fig. 6).

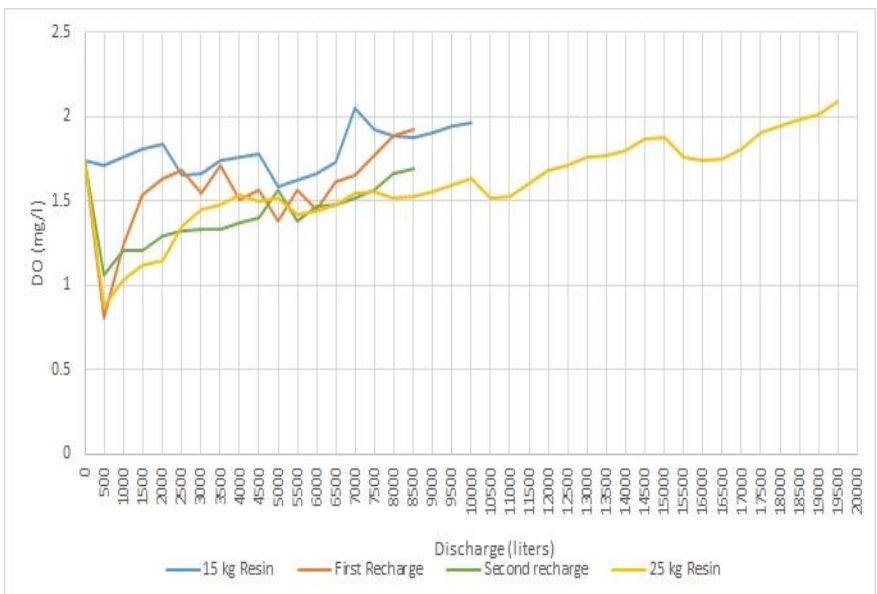

Figure 6: Results of Dissolved Oxygen

\subsection{Automation of Water Softener}

In this study the main objective was to make an optimum model of water softener. Therefore, it was designed accordingly, and different test and experiments were taken place to make different analysis. After completing all the experiments and observing all the results of the plant it was decided to make this system automatic which can give required results and run automatically.

Therefore, it was decided to change the manual valve of softening plant and installed an automatic valve for smooth running and to acquire necessary results. After installing new valve more experiments were performed for the adjustment of the valve.

It was decided to set a constant value of hardness taken from the system. According to given standard limits and specific requirement of the soft water it was decided to set the value of hardness around $100 \mathrm{mg} / \mathrm{l}$. Then experiment was performed again, and results are given below: 


\begin{tabular}{|c|c|c|c|c|c|c|c|c|}
\hline \multicolumn{10}{|c|}{ Results of Total Hardness } \\
\hline \multicolumn{9}{|c|}{ Recharge II } \\
\hline
\end{tabular}

under:

Table 1: Hardness value for Automatic Valve settings

According to the given results it has been observed that there were three times recharging of ion exchange resins were occurred. In first recharge it has been seen that the volume of 7000 liters of water passed through the plant to get to the value of $104 \mathrm{mg} / \mathrm{l}$ which was around $100 \mathrm{mg} / \mathrm{l}$ as we set that earlier. Then it was recharged again, this time 6000 liters of sample water passed through the plant and we get $120 \mathrm{mg} / \mathrm{l}$, final value of hardness. In third regeneration or recharging of the ion exchange resins 6500 liters of water passed through and the last value of hardness was 106 $\mathrm{mg} / \mathrm{l}$. So as an average 6500 liters of water passed through plant to get to the value of $100 \mathrm{mg} / \mathrm{l}$ hardness.

In automatic valve there was setting of recharging with respect to time. Therefore, it was estimated that for domestic purpose the average daily consumption of water stands around 1000 liters for six persons so timing of recharging of the water softener is set after 5 days. The timing of regeneration set for 30 minutes, for backwashing, brine refill and fast rinse 5 minutes time set for each process. These all processes of recharging will be done automatically according to the given schedule.

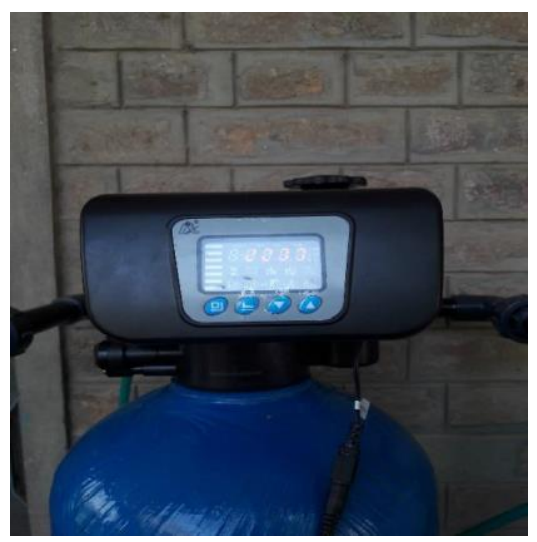

Figure 7: Multi-Functional Flow Control Valve for Water Treatment

\section{Example of Cost Analysis of Water Softener:}

Average consumption of water per capita per day $=80$ gallons $[18,19]$.

Average consumption for 6 persons per day $=480$ gallons

Average consumption for 6 persons per month $=480 \times 30=14400$ gallons Rate of WASA water supply per thousand gallons per month $=40 \mathrm{PKR}$ (WASA, 2006)

So,

Rate of 1 gallon per month $=0.04$ PKR

Bill for 6 persons per month $=14400 \times 0.04=576 \mathrm{PKR}$

Now, operational cost of water softener; it required PPF filters to be changed after every four months. So,

Cost of one PPF filter $=250 \mathrm{PKR}$

Cost of two PPF filter $=250 \times 2=500 \mathrm{PKR}$

Cost of PPF filters per month $=500 / 4=125$ PKR

Graphical representation of cost analysis of water softener is given as

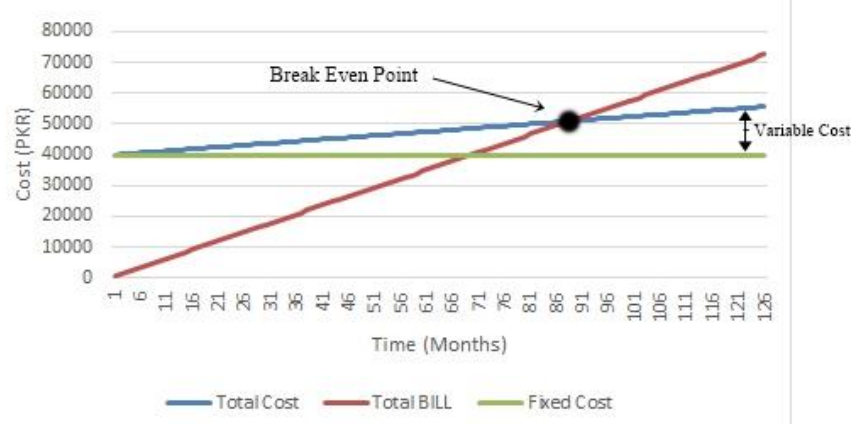

Figure 8: Cost Analysis (Break Even Point)

The above graph shows break-even point of the water softener plant. In this graph time with monthly duration is on $\mathrm{x}$-axis and cost in PKR is on yaxis. This graph represent fixed cost of the plant is 40000 PKR. The breakeven point of the plant is at 89's month and at the cost of 51000 PKR. So, after 89 months or 7.41 years the plant working will be on profit on the basis of cost.

\section{REFERENCES}

[1] Kadir, A.N.N., Shahadat, M., Ismail, S. 2016. Formulation study for softening of hard water using surfactant modified bentonite adsorbent coating. Applied Clay Science, 137, 168-175.

[2] Nabi, S.A., Shahadat, M., Bushra, R., Shalla, A.H., Azam. A. 2011. Synthesis and characterization of nano-composite ion-exchanger; its adsorption behavior. Colloids and Surfaces B: Biointerfaces, 87(1), 122128.

[3] World Health Organization. 2003. Molybdenum in drinking-water: background document for development of WHO guidelines for drinkingwater quality.

[4] Pakistan Council of Research in Water Resources. 2007. Water Quality Status, 5th Technical Report. Government of Pakistan, Islamabad. 30-37.

[5] Reddiroot'r. 2016. Problems and Solutions for Hard Water Buildup. Accessed on March 26 March 2017. http://www.reddiplumbingwichita.com/blog/general/problems-andsolutions-for-hard-water-buildup.

[6] McFarland, M.L., Provin, T.L., Boellstorff, D.E. 2015. Drinking Water Problems: Corrosion.

[7] Heidekamp, A.J., Lemley. 2005. Hard water CCE Water Bulletine. $\begin{array}{llll}\text { Accessed } & \text { on } & 18 & \text { March }\end{array}$ http://waterquality.cce.cornell.edu/publications/CCEWQ-50HardWater.pdf.

[8] Cameron, B.A. 2011. Detergent considerations for consumers: laundering in hard water - How much extra detergent is required. J. Extension, 49, 1-11.

[9] USGS, the USGS water science school, 2016. Water Questions and Answers. Accessed on 2 December 2016. https://water.usgs.gov/edu/qahome-percapita.html.

[10] Begum, A., Ramaiah, M., Khan I., Veena. K. 2009. Heavy metal pollution and chemical profile of Cauvery River water. Journal of Chemistry, 6(1), 47-52.

[11] Stephen, L. 2013. Hard water and water softening. Accessed on 12 January 2017. http://www.chem1.com/CQ/hardwater.html. 
[12] Charles, E. 2003. Soap. Accessed on 2 January 2017. http://www.elmhurst.edu/ chm/vchembook/554soap.html.

[13] Alan, R. 2013. Soft Water V. Hard Water in Plumbing, Pools and Hot Tubs Spas. Accessed on 27 December 2016. http://www.articlesnatch.com/Article/Soft-Water-V--Hard-Water-InPlumbing--Pools-And-Hot-Tubs-Spas/1361419.

[14] Water Softeners, Canadian Mortgage and Housing Corporation, 2010. Accessed on 24 December 2016. https://www.revolvy.com/main/index.php?s=Water\%20softening\&item -type=topic.

[15] Water softening. 2017, May 15. In Wikipedia, The Free Encyclopedia. Retrieved 04:45, June 30, 2017, from https://en.wikipedia.org/w/index.php?title=Water_softening\&oldid=780 545745 .
[16] Srinivasan, R., G. A. Sorial. 2009. Treatment of perchlorate in drinking water: a critical review. Separation and Purification Technology, 69(1), 7-21.

[17] Tahir, M.A., Rasheed, R., Asghar, M., Anwar, I. 2003. Instruction manual for water quality analysis. Pakistan council of research and water resources. Islamabad.

[18] USGS - Water Quality Information, 2013. United States Geographical Survey: Water Hardness and Alkalinity. J. Geol. Accessed on 21 January 2017. http://water.usgs.gov/owq/hardness-alkalinity.html.

[19] Water and Sanitation Agency. 2006. The Punjab Gazette. Accessed on 23 June 2017. http://wasafaisalabad.gop.pk/assets/uploads/Documents/14/Tariff\%2 0for\%20Water\%20\&\%20Sanitation\%20Agency.pdf 